\title{
Polypropylene prosthesis as cicatricial adjuvant after fasciotomy for compartment syndrome of the foot: Case report
}

\begin{abstract}
The acute foot compartment syndrome is uncommon and occurs after high energy trauma. Your treatment is considered an orthopedic emergency and a fasciotomy becomes needed. However, after the inicial fase of damage control, the cover up of the incision is necessary. That can be done on the primary moment through parcial skin grafting or delayed primary, through the same technique or through direct suture. As an alternative, this case describes the use of polypropylene prosthesis, inicially described in musculoskeletal trauma of finger tips, as an adjunct to the healing process of foot fasciotomies. The main benefits of this technique are the achievement of one single surgical procedure and the absence of the typical morbidity that comes with skin grafting.
\end{abstract}

Keywords: compartment syndromes, fasciotomy, wound healing, foot, polypropylene
Volume I3 Issue 5 - 202I

\author{
José Martins Juliano Eustáquio,' Leonardo \\ Soares Ataíde Oliveira, ${ }^{2}$ Décio José de \\ Oliveira Júnior, ${ }^{2}$ Thayla Carriço Mendes, ${ }^{2}$ \\ Alberto Martins Fontoura Borges,' Octávio \\ Barbosa $\mathrm{Neto}^{3}$ \\ 'Mário Palmerio Hospital, Medical Residency in Orthopedics \\ and Traumatology, University of Uberaba (UNIUBE), Uberaba, \\ Minas Gerais, Brazil \\ ${ }^{2}$ Academic of the Medicine Course at the University of Uberaba \\ (UNIUBE), Uberaba, Minas Gerais, Brazil \\ ${ }^{3}$ Federal University of Triângulo Mineiro (UFTM), Uberaba, Minas \\ Gerais, Brazil
}

\author{
Correspondence: José Martins Juliano Eustaquio, Mário \\ Palmerio Hospital, University of Uberaba (UNIUBE), Av. Cecilia \\ Palmerio, s/n, Uberaba, MG, Brazil. CEP 38050175 , \\ Email zemartinsjuliano@hotmail.com
}

Received: September 29, 2021 | Published: October 20, 202

\section{Introduction}

The acute foot compartment syndrome (FCS) is relatively rare ${ }^{1,2}$ and occurs, in general, after high-energy injuries, especially due to fracture-dislocations or crush injuries. ${ }^{3}$ It's diagnosis must always be suspected after events like these, since the failure in proper treatment may cause severe and permanent sequelas. ${ }^{4,5}$

The emergency treatment of the Acute Compartment Syndrome (ACS) is accomplished through fasciotomy, which provides the local decompression of the neurovascular and musculoskeletal structures. ${ }^{6}$ On the foot, the fasciotomy can be performed through two or three incisions, according to the number of affected compartiments. ${ }^{4}$ Another procedure described on this segment are the multi stab incisions over the intermetatarsal spaces ("pie crusting"), which makes the healing process easier. ${ }^{5}$

On most cases, after the inicial period of damage control, a new surgical intervention is scheduled to accomplish the definitive closure of the wound. This procedure can be performed directly, through skin suture, or indirectly, through a biological material or procedure, which will act as an adjunct to the healing process. It can also be done by split-thickness skin grafting, which may be performed primarily (in the acute phase) or delayed primary (after the damage control phase). ${ }^{4}$

In analogy to the good results of fingertip injuries ${ }^{10}$ it is assumed that the use of synthetic material originated from polypropylene, easily available through the flexible recipient of $0,9 \%$ saline solution, may be used as a primary and temporary cover of the foot incisions as well. There is no datum on literature that makes a reference to the use of biological or synthetic material with this end when it comes specifically to the treatment of the FCS. The object of this of this case report was to describe the use of polypropylene prosthesis, known for the treatment of fingertips primary injuries, as an adjunct to the healing process after foot's fasciotomy.

\section{Case report}

Female patient, forty-four years old, domestic, no comorbidities, sought care in an Emergency Care Unit, due to blunt trauma on right foot (five kilograms object drop), after approximately 2 hours. On orthopedic physical examination, she presented edema $(3+/ 4+)$ and significant pain on dorsum of right foot, without neurovascular injuries. The radiograph and computed tomography of the foot showed fractures at the base of the $2^{\circ}, 3^{\circ}$ and $4^{\circ}$ metatarsal, with no joint damage (Figures 1A \& 1B).
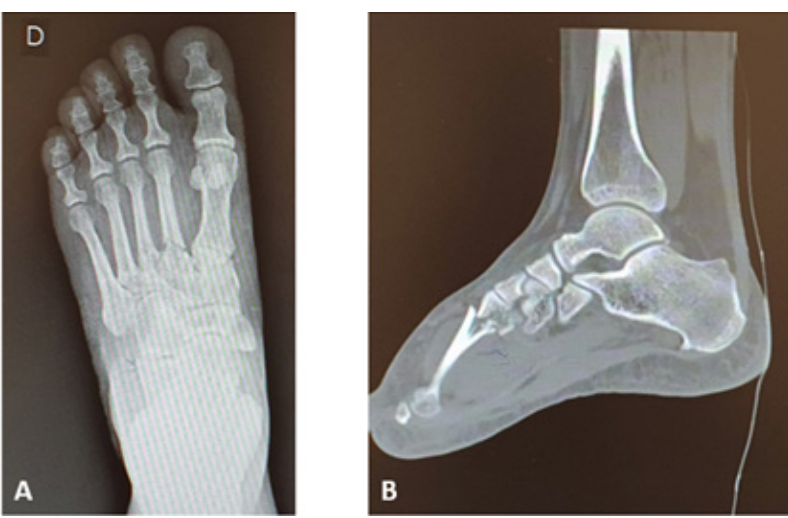

Figure I Radiograph (A) and computed tomography imaging (B) of the foot indicating fracture at the base of the $2^{\circ}, 3^{\circ}$ and $4^{\circ}$ metatarsal. Source:Author's personal arquive.

Initially, an attempt of conservative treatment was made, under observation at the Emergency Room due to the intensity of the pain and the potential for evolving to ACS. After approximately 6 hours of observation at the Unit, there was a progressive worsening of the pain and the foot edema. She also complaint of worsening of the pain during hallux passive extension, and all of those symptoms were 
compatible with the diagnosis of ACS. Therefore, it was indicated the perform of decompressive fasciotomy.

To perform the procedure, the patient underwent spinal anesthesia. After that, the fasciotomy occurred through two dorsal incisions (lateral and medial) (Figure 2A). At this point, to reduce additional damage of soft tissues, the mechanic stabilization of the fractures was performed through Kirschner wires $1.5 \mathrm{~mm}$, which was placed transversely (Figure 2B).
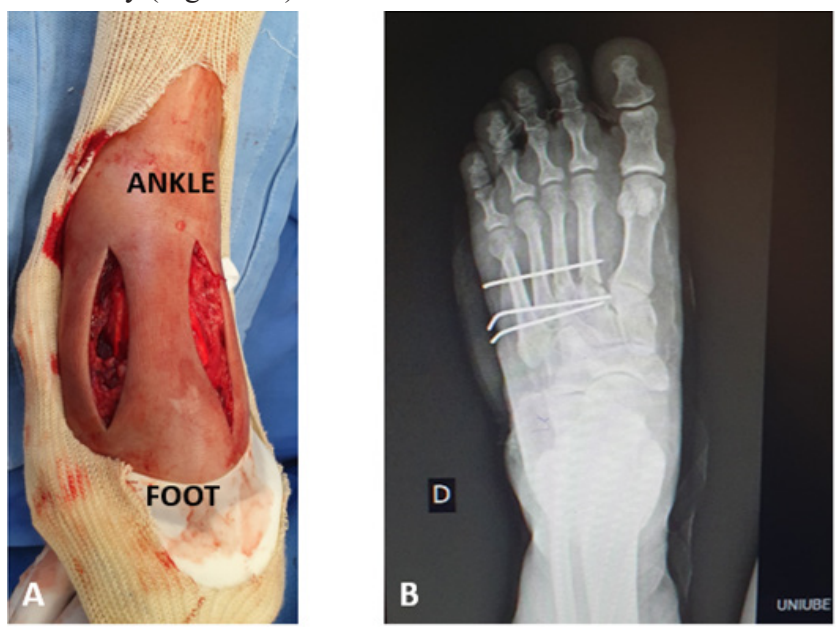

Figure 2 Clinical (A) and radiograph imaging (B) in the immediate postoperative of fasciotomy and osteosynthesis of the foot fractures. Source: Author's personal arquive.

To help the fasciotomy's incisions healing process, a polypropylene prosthesis (flexible recipient of $0,9 \%$ saline solution) with the necessary size to a full cover was placed in each incision. The prosthesis was fixated to the skin with non-absorbable thread Nylon $3.0 \mathrm{~mm}$, without exerting tension on the skin (Figure 3A \& 3B). The antibiotic's use was limited to the usual prophylactic period (up to 24 hours after surgery).
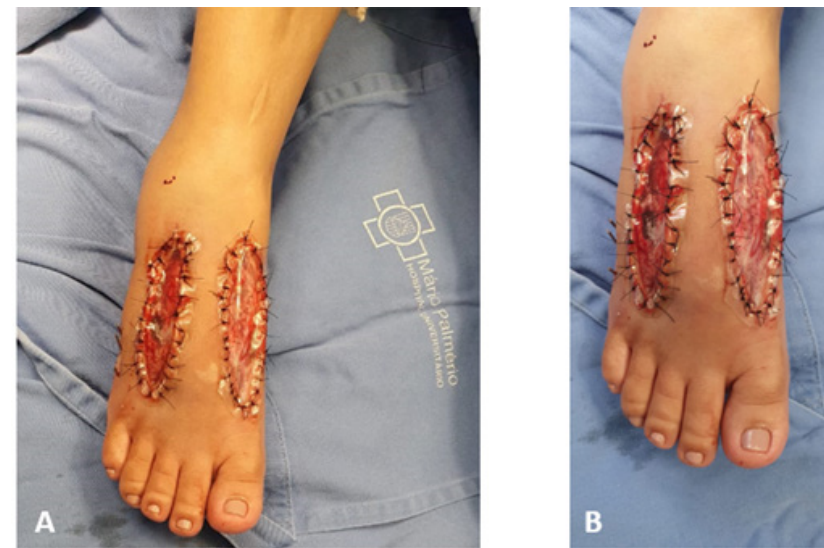

Figure 3 Clinical imaging in the immediate postoperative after placing polypropylene prosthesis $(\mathrm{A})$. The absence of tension between the skin edges and prosthesis is observed (B). Source:Author's personal arquive.

She was instructed to perform daily dressings, with the placement of gauze and crepe bandage on the dorsum of the foot. On all of her outpatient appointments, which were fortnightly, the careful inspection of the wound was made, focusing especially at the possibility of the dehiscence of the suture between the skin and the prosthesis. This is a potential complication of this technique and would compromise the wound's healing process. However, this complication was not observed (Figure 4A \& 4B).
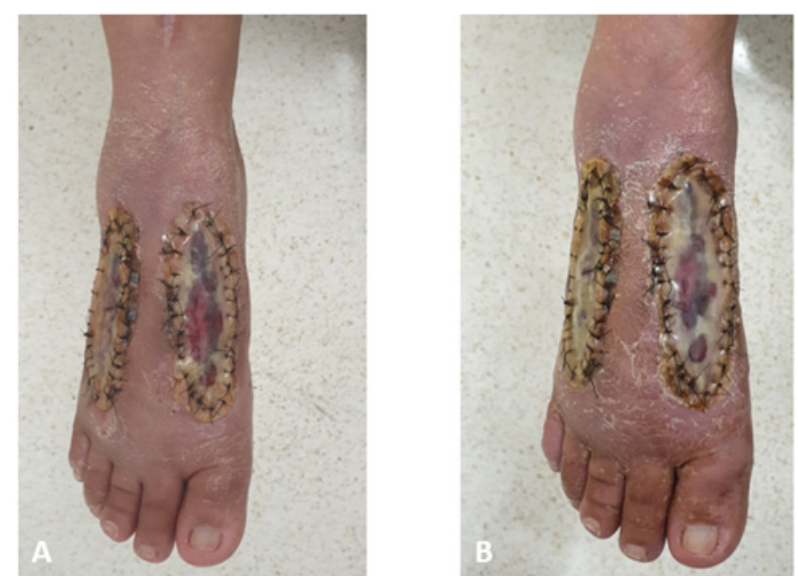

Figure 4 Clinical imaging of the foot, during outpatient appointments, after 0 I (A) and 04 (B) weeks of postoperative. Source:Author's personal arquive.

On week 6 of post-operative, the Kirschner wire were removed after the radiographic confirm of fracture consolidation. The polypropylene prosthesis were kept until week 10 of post-operative, when it was seen a complete healing of the wounds, but there were still scab present (Figure 5A). Those scabs completely regressed after 2 more weeks (Figure 5B).
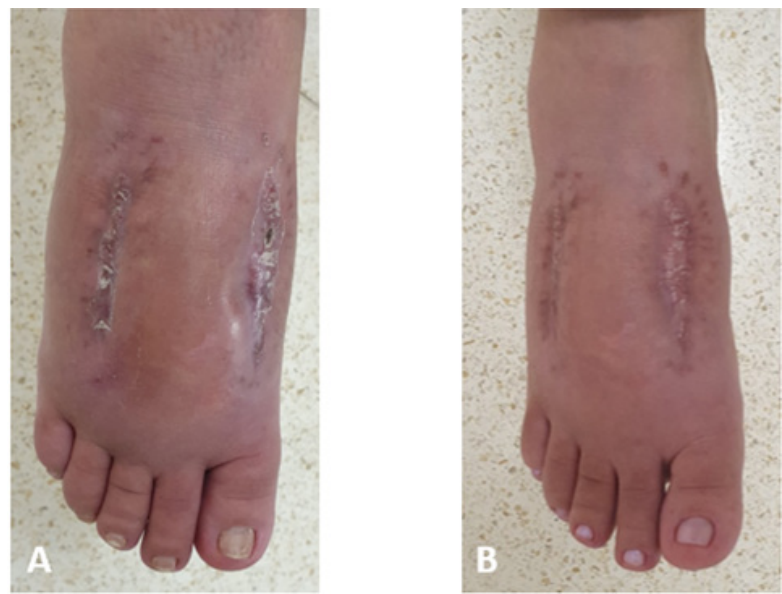

Figure 5 Foot's healing process, right after the removal of the polypropylene prosthesis, with 10 (A) and 12 (B) weeks of postoperative. Source: Author's personal arquive.

The patient started physiotherapy right after the removal of the Kirschner wires, and she was allowed to release progressive partial load and exercises to gain range of motion of the foot and ankle ipsilaterally. Since the patient remained with the prosthesis for 4 more weeks after that, the physiotherapy team was instructed not to perform physical therapy such cryotherapy, transcutaneous electrical nerve stimulation, among others, on the right foot. When the polypropylene was removed, the patient had normal range of motion and sensibility in the right foot and ankle. Furthermore, there was no development of chronic pain at any of these body segments.

\section{Discussion}

This case report shows an affective and low-cost alternative as an adjunct to the healing process of foot fasciotomy incisions with no need to a new surgical approach. This procedure's main benefit is that only one surgical procedure is needed, without the typical need to reaproach and perform the definitive closure of the incisions. This 
single aproach offers many benefits to the pacient, since there is no new surgical stress, and offers benefits to the health system as well, because it represents lower financial costs.

However, it is known that there is a potention need to review the surgical procedure for debridament of necrotic tissues, according to the severity of the trauma and the time elapsed until the fasciotomy. ${ }^{11}$ Therefore, in more complex cases, it is prudent not to perform the technique with a polypropylene prosthesis at the acute moment of fasciotomy. Besides, it is commun to use skin grafting to close foot's fasciotomy incisions, that can be done primarily or through delayed primary technique., ${ }^{42}$ The use of polypropylene prosthesis avoids the necessity of those skin grafts, which causes less morbidity in the donor area and lower rates of complications, especially those related to biological non-integration.

The technique that uses polypropylene prosthesis offers biological and mechanical conditions to a proper healing process of the wound. ${ }^{10}$ The polypropylene's presence induces a propitious biochemical and cellular environment and offers mechanical protection to the neoformed tissue. Another important aspect is that the prosthesis is considered inert due to its external positioning, which differs from another implants of the same nature used in other biological systems. ${ }^{13,14}$

During the procedure, it is important that the suture between the polypropylene prosthesis and the skin edges does not have excessive tension, since it might predispose dehiscence before the heling process is complete. Furthermore, the prosthesis must be placed in direct contact with the deep tissues, as the existence of a dead space might cause a hypertrophic scar at the area. This case report's description presents to the cientific comunity one more option of a definitive treatment to foot injuries. It was showed here as a adjunct procedure to help the healing process after a fasciotomy, but it also can be expanded to other indications with similar purpose.

\section{Conclusion}

The polypropylene prosthesis placed primarily is a viable alternative as an adjunct method to the healing process of the fasciotomy's incision after a foot compartment syndrome.

\section{Acknowledgments}

None.

\section{Conflicts of interest}

The authors declare no conflicts of interest.

\section{Funding}

None.

Place where the work was developed Mário Palmerio Hospital, University of Uberaba (UNIUBE), Uberaba, Minas Gerais, Brazil.

\section{References}

1. Towater LJ, Heron S. Foot compartment syndrome: a rare presentation to the Emergency Department. J Emerg Med. 2013;44(2):e235-e238.

2. Fulkerson E, Razi A, Tejwani N: Review: Acute compartment syndrome of the foot. Foot Ankle Int. 2003;24(2):180-187.

3. Thakur NA, McDonnell M, Got CJ, et al. Injury patterns causing isolated foot compartment syndrome. J Bone Joint Surg Am. 2012;94(11):1030 1035 .

4. Dodd A, Le I. Foot compartment syndrome: diagnosis and management. $J$ Am Acad Orthop Surg. 2013;21(11):657-664.

5. Dunbar RP, Taitsman LA, Sangeorzan BJ, et al. Technique tip: Use of "pie crusting" of the dorsal skin in severe foot injury. Foot Ankle Int. 2007;28(7):851-853.

6. Lintz F, Colombier JA, Letenneur J, et al. Management of long-term sequelae of compartment syndrome involving the foot and ankle. Foot Ankle Int. 2009;30(9):847-853.

7. Mortensen SJ, Orman S, Serino J, et al. Factors Associated with Development of Traumatic Acute Compartment Syndrome: A Systematic Review and Meta-analysis. Arch Bone Jt Surg. 2021;9(3):263-271.

8. Temple HT, Malinin TI. Orthobiologics in the Foot and Ankle. Foot Ankle Clin. 2016;21(4):809-823.

9. Kunze KN, Hamid KS, Lee S, et al. Negative-Pressure Wound Therapy in Foot and Ankle Surgery. Foot Ankle Int. 2020;41(3):364-372.

10. Figueiredo LA, Ribeiro RS, Melo ALB, et al. Uso da prótese de polipropileno para o tratamento das lesões em ponta de dedo. Descrição de técnica cirúrgica e resultados. Rev Bras Ortop. 2017;52(6):685-692

11. Lutter C, Schöffl V, Hotfiel T, et al. Compartment Syndrome of the Foot: An Evidence-Based Review. J Foot Ankle Surg. 2019;58(4):632-640.

12. Godoy-Santos AL, Schepers T. Soft Tissue Foot \& Ankle Group. Soft-tissue injury to the foot and ankle: literature review and staged management protocol. Acta Ortop Bras. 2019;27(4):223-229.

13. Sternschuss G, Ostergard DR, Patel H. Post-implantation alterations of polypropylene in the human. J Urol. 2012;188(1):27-32.

14. Donati M, Brancato $\mathrm{G}$, Grosso $\mathrm{G}$, et al. Immunological reaction and oxidative stress after light or heavy polypropylene mesh implantation in inguinal hernioplasty: A CONSORT-prospective, randomized, clinical trial. Medicine (Baltimore). 2016;95(24):e3791 